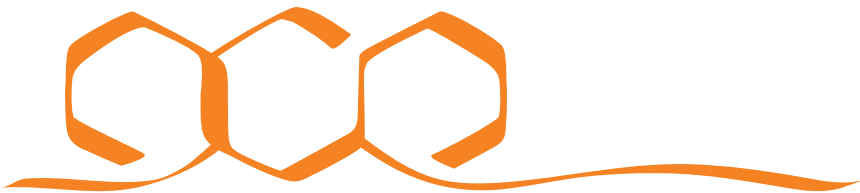 COMMUNICATIONS CHEMISTRY
}

REVIEW ARTICLE

\section{Aluminum electrolytes for Al dual-ion batteries}

\author{
Kostiantyn V. Kravchyk (1) ${ }^{1,2 \bowtie}$ \& Maksym V. Kovalenko (iD) ${ }^{1,2 \bowtie}$
}

In the search for sustainable energy storage systems, aluminum dual-ion batteries have recently attracted considerable attention due to their low cost, safety, high energy density (up to $70 \mathrm{kWh} \mathrm{kg}^{-1}$ ), energy efficiency (80-90\%) and long cycling life (thousands of cycles and potentially more), which are needed attributes for grid-level stationary energy storage. Overall, such batteries are composed of aluminum foil as the anode and various types of carbonaceous and organic substances as the cathode, which are immersed in an aluminum electrolyte that supports efficient and dendrite-free aluminum electroplating/stripping upon cycling. Here, we review current research pursuits and present the limitations of aluminum electrolytes for aluminum dual-ion batteries. Particular emphasis is given to the aluminum plating/stripping mechanism in aluminum electrolytes, and its contribution to the total charge storage electrolyte capacity. To this end, we survey the prospects of these stationary storage systems, emphasizing the practical hurdles of aluminum electrolytes that remain to be addressed.

$\mathrm{T}$ he integration of intermittent renewables into the grid is directly linked to the deployment of stationary energy storage systems at the terawatt scale, enabling grid stabilization. From this perspective, in addition to conventional energy storage means, such as pumpedstorage hydroelectricity (PSH), stationary batteries will be of significant importance ${ }^{1}$. Loosely speaking, the assessment of the battery technologies for stationary storage applications can be made by comparing their capital cost $\left(\$ \mathrm{~kW}^{-1} \mathrm{~h}^{-1} \mathrm{cycle}^{-1}\right)$ to that of $\mathrm{PSH}$, which is presently the predominant stationary storage system. Consequently, stationary batteries should possess an exceptional cycling stability (thousands of cycles), environmental friendliness, low $\mathrm{CO}_{2}$ footprint, and low cost. In this framework, the exploration of batteries composed of $\mathrm{Na}^{2,3}, \mathrm{~K}^{4}, \mathrm{Mg}^{5,6}$, and $\mathrm{Al}^{7-9}$ as earth-abundant metals has become a primary research target in recent years. Notably, batteries that employ $\mathrm{Al}$ metal as an anode can harness numerous advantages, such as a high charge storage capacity of $2977 \mathrm{mAh} \mathrm{g}^{-1}$ of $\mathrm{Al}$, its natural abundance, and safety ${ }^{10-15}$. Furthermore, $\mathrm{Al}$ can be reversibly deposited and stripped in chloroaluminate ionic liquids with a high coulombic efficiency and without the formation of dendrites ${ }^{16,17}$. In this context, a new electrochemical concept called the aluminum dual-ion battery (ADIB) has recently attracted significant attention. ADIBs have a high potential for grid-scale energy storage applications

\footnotetext{
${ }^{1}$ Laboratory for Thin Films and Photovoltaics, Empa - Swiss Federal Laboratories for Materials Science and Technology, Überlandstrasse 129, CH-8600 Dübendorf, Switzerland. ${ }^{2}$ Laboratory of Inorganic Chemistry, Department of Chemistry and Applied Biosciences, ETH Zürich, Vladimir-Prelog-Weg 1, CH8093 Zürich, Switzerland. ${ }^{\circledR}$ email: kravchyk@inorg.chem.ethz.ch; mvkovalenko@ethz.ch
} 
owing to their low cost, relatively high energy densities of up to $\approx 70 \mathrm{Wh} \mathrm{kg}^{-118}$, and cyclic stability. In this review, we discuss recent developments in $\mathrm{Al}$ electrolytes for $\mathrm{ADIBs}$ covering the topics of charge storage capacity and the operating mechanism of ADIBs. In addition, we analyze in detail the impacts of acidity, ionic conductivity, the $\mathrm{Al}^{3+} / \mathrm{Al}$ redox potential, and the electrochemical voltage window of the $\mathrm{Al}$ electrolytes on the performance of ADIBs. Finally, with respect to the practical application of ADIBs, the compatibility of current collectors with Al electrolytes is covered in the last section of this review.

\section{Historical aspects of the development of Al electrolytes for ADIBs}

Although the research on $\mathrm{Al}$ electrolytes for ADIBs may appear to be a new subject, this is a misconception. The employment of $\mathrm{Al}$ electrolytes in ADIBs based on molten salts was assessed for the first time in the 1970 s by Fouletier et al. ${ }^{19}$ Fouletier's ADIB was composed of metallic aluminum and graphite as negative and positive electrodes, respectively, which were immersed into molten $\mathrm{LiCl} / \mathrm{AlCl}_{3}$ salts (ca. $140{ }^{\circ} \mathrm{C}$ ). In 1988, Gifford et al. ${ }^{20}$ extended research on ADIBs towards the use of roomtemperature ionic liquids (RTILs) based on imidazolium chemistry $\left(\mathrm{AlCl}_{3}: 1,2\right.$-dimethyl-3-propylimidazolium chloride). In 2015, $\mathrm{Al}$ electrolytes received a great deal of attention since the publication of Dai et al. ${ }^{21}$ on ADIBs employing a metallic $\mathrm{Al}$ anode, two synthetic forms of graphite as the cathode (CVD-grown graphitic foam and pyrolytic graphite) and 1-ethylmethylimidazolium ionic liquid electrolyte $\left(\mathrm{AlCl}_{3} \text { :EMIMCl}\right)^{21}$. Dai's ADIB showed a high reversibility over thousands of cycles and graphite cathodic capacities of up to $67 \mathrm{mAh} \mathrm{g}^{-1}$. Those first publications have initiated the exploration of deep eutectic solvents (DESs) as $\mathrm{Al}$ electrolytes for ADIBs by Dai et al. ${ }^{22,23}$, Jiao et al. ${ }^{24-26}$, and others ${ }^{27-31}$. A schematic illustration of the different classes of $\mathrm{Al}$ electrolytes presently used in ADIBs is shown in Fig. 1a. A comparison of the various $\mathrm{Al}$ electrolytes with respect to their density, viscosity, ionic conductivity, theoretical charge storage capacity, and cost is given in Table 1.

\section{Working principle of ADIBs and Al electrolytes based on RTILs}

The basic configuration of ADIBs comprises a carbonaceous (graphite, zeolite-templated carbon (ZTC), or graphene) or organic positive electrode, chloroaluminate ionic liquid electrolyte and metallic aluminum anode as demonstrated in Fig. 1b. ADIBs operate as an electrochemical energy storage system employing reversible intercalation/insertion of the $\mathrm{AlCl}_{4}{ }^{-}$anion species into the positive electrode upon charge (oxidation). Concomitantly, the electroplating of aluminum occurs at the negative electrode of ADIBs. The working principle of ADIBs can be represented by the following cathodic and anodic half-reactions during charge:

On the negative electrode : $4 \mathrm{Al}_{2} \mathrm{Cl}_{7}^{-}+3 \mathrm{e}^{-} \leftrightarrow 7 \mathrm{AlCl}_{4}^{-}+\mathrm{Al}$,

On the positive electrode $: x \mathrm{C}+\mathrm{AlCl}_{4}^{-} \leftrightarrow \mathrm{C}_{x}\left(\mathrm{AlCl}_{4}^{-}\right)+\mathrm{e}^{-}$,

where $\mathrm{C}$ is graphite $^{32}, \mathrm{ZTC}^{33}$, graphene $\mathrm{B}^{34}$ or organic active material $^{35,36}$. Consequently, the mechanism of ADIBs is significantly different from the "rocking-chair" metal-ion batteries. There is no one-directional motion of $\mathrm{Al}^{3+}$ ions from the positive to the negative electrodes. Al species are depleted from the chloroaluminate ionic liquid during the charge of ADIBs and are consumed by both electrodes. The Al electrolytes that are used in $\mathrm{ADIBs}$ play a double function: they support the $\mathrm{Al}$ plating/stripping process and act as the source of $\mathrm{AlCl}_{4}{ }^{-}$ions being needed for the intercalation/insertion into the positive electrode during charge. Consequently, ADIB term is applied for batteries, were electrolyte acts as a source of two types of ions (i.e., $\mathrm{Al}_{2} \mathrm{Cl}_{7}^{-}$and $\mathrm{AlCl}_{4}^{-}$) required for electrochemical energy storage. Thus, the composition of the electrolyte is changing upon charge and discharge, contrary to "rocking-chair" Al-ion battery systems, where electrolyte acts exclusively as a transmitter of the ions. The most conventional example of an $\mathrm{Al}$ electrolyte is a mixture of aluminum chloride and other chlorides comprising an organic cation, for instance, 1-butyl-3-methylimidazolium chloride (BMIM) and 1-ethyl-3methylimidazolium chloride (EMIM). As a consequence of the acid-base interactions between $\mathrm{AlCl}_{3}$ (Lewis acid) and $\mathrm{Cl}^{-}$(Lewis base), the salt mixture becomes a liquid at room temperature, forming an RTIL. The latter is composed of $\mathrm{AlCl}_{4}{ }^{-}$anions that are charge-balanced with organic cations. The RTIL with an excess of Lewis acid $\mathrm{AlCl}_{3}$ over Lewis base EMIMCl is comprised of both $\mathrm{AlCl}_{4}{ }^{-}$and $\mathrm{Al}_{2} \mathrm{Cl}_{7}{ }^{-}$ions. Importantly, $\mathrm{ADIBs}$ are operational only in acidic formulations. Solely $\mathrm{Al}_{2} \mathrm{Cl}_{7}^{-}$ions enable the electroplating of aluminum, which therefore, occurs only in chloroaluminate melts with an excess of $\mathrm{AlCl}_{3}{ }^{37-46}$. As a result, the charge storage capacity of the chloroaluminate melt is a function of the concentration of $\mathrm{Al}_{2} \mathrm{Cl}_{7}^{-}$ions in the RTIL. Electroplating, and therefore, the charging process stops when no $\mathrm{Al}_{2} \mathrm{Cl}_{7}{ }^{-}$ions are left in the ionic liquid, which results in the formation of the neutral melt $\left(\mathrm{AlCl}_{3}: \mathrm{EMIMCl}=1\right)$. The highest molar ratio $(r)$ between $\mathrm{AlCl}_{3}$ and EMIMCl that forms an RTIL is ca. $2: 1 . \mathrm{AlCl}_{3}$ does not dissolve at higher molar ratios. Apart from the ionic melts based on $\mathrm{AlCl}_{3} /$ EMIMCl, other RTILs have also been recently reported to be composed of 1-methyl-3-propylimidazolium chloride (MPIMCl ${ }^{47}$, benzyltriethylammonium chloride (TEBACl) ${ }^{48}$, and 1,2-dimethyl3-propylimidazolium chloroaluminate (DMPIMCl) ${ }^{49}$.

Figure 2 illustrates the impact of acidity $r$ on the charge storage capacity of the chloroaluminate ionic liquid electrolytes, which can be, in fact, called anolytes. The theoretical gravimetric and volumetric capacities of the ionic liquid $C_{\text {an }}$ can be calculated as follows:

$$
\begin{aligned}
& \text { Gravimetric } C_{\mathrm{an}}=\frac{F x(r-1)}{r M_{\mathrm{AlCl}_{3}}+M_{\mathrm{ACl}}}\left(\mathrm{mAhg}^{-1}\right), \\
& \text { Volumetric } C_{\mathrm{an}}=\frac{F x(r-1) \rho}{r M_{\mathrm{AlCl}_{3}}+M_{\mathrm{ACl}}}\left(\mathrm{mAhg}^{-1}\right),
\end{aligned}
$$

where $F=26.8 \times 10^{3} \mathrm{mAh} \mathrm{mol}^{-1}$ (the Faraday constant), $x=\frac{3}{4}$ (number of electrons that are used to reduce $1 \mathrm{~mol}$ of the $\mathrm{Al}_{2} \mathrm{Cl}_{7}{ }^{-}$ ions), $M_{\mathrm{AlCl} 3}$ is the molar mass of $\mathrm{AlCl}_{3}\left(\mathrm{~g} \mathrm{~mol}^{-1}\right), M_{\mathrm{ACl}}$ is the molar mass of the $\mathrm{Cl}^{-}$salt $\left(\mathrm{g} \mathrm{mol}^{-1}\right), r$ is the $\mathrm{AlCl}_{3}: \mathrm{ACl}$ molar ratio, and $\rho$ is density of the chloroaluminate melt $\left(\mathrm{g} \mathrm{mL}^{-1}\right)$. A detailed description of the derivation of Eqs. 3 and 4 can be found in ref. 50 .

For instance, the gravimetric charge storage capacities of the $\mathrm{AlCl}_{3}$ : EMIMCl ionic liquid are equal to $19 \mathrm{mAh} \mathrm{g}^{-1}$ and $48 \mathrm{mAh} \mathrm{g}^{-1}$ for $r=1.3$ and $r=2$, accordingly. Notably, these capacities define the overall energy density of ADIBs ${ }^{14,18,50-57}$. Moreover, it should be pointed out that these theoretical capacities are not always achievable experimentally, i.e., they depend on practically relevant experimental conditions and on whether $\mathrm{Al}_{2} \mathrm{Cl}_{7}$ - ions can be fully depleted for $\mathrm{Al}$ electroplating. To figure out this point, recently, Kravchyk et al. ${ }^{58}$ assembled the anolyte-limited cell in a three-electrode configuration with a significant excess of graphite cathode (anolyte-limited cell). Upon these measurements (Fig. 3a), in addition to the voltage profile of the full cell, the profiles for both positive and negative electrodes were recorded. It was demonstrated that the voltage profile at the negative electrode $\left(E_{\mathrm{CE}}\right)$ remained relatively stable during charging for $15 \mathrm{~min}$. Upon further charging, however, the voltage dropped 
a

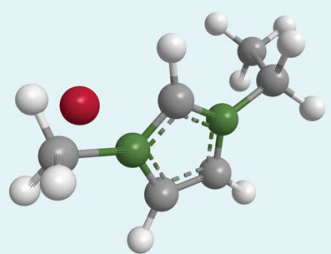

Imidazolium-based (EMIMCI)

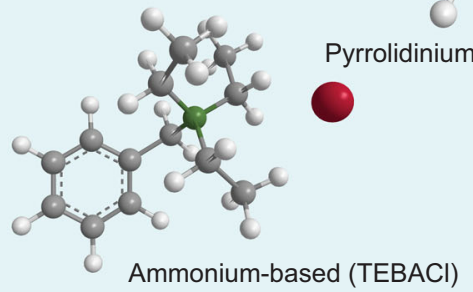

Inorganic molten salts

Deep eutectic solvents

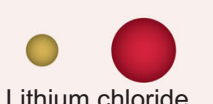

Lithium chloride

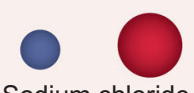

Sodium chloride

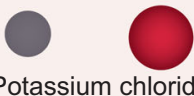

Potassium chloride

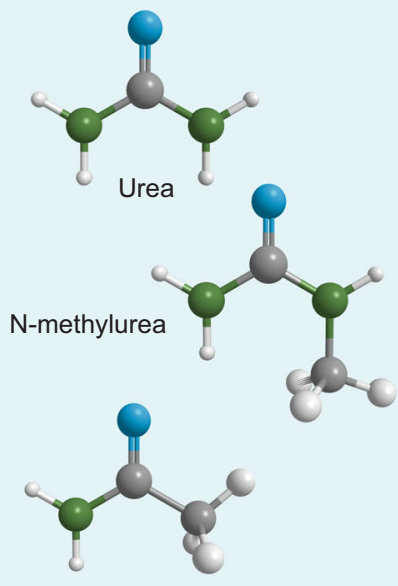

Acetamide

b
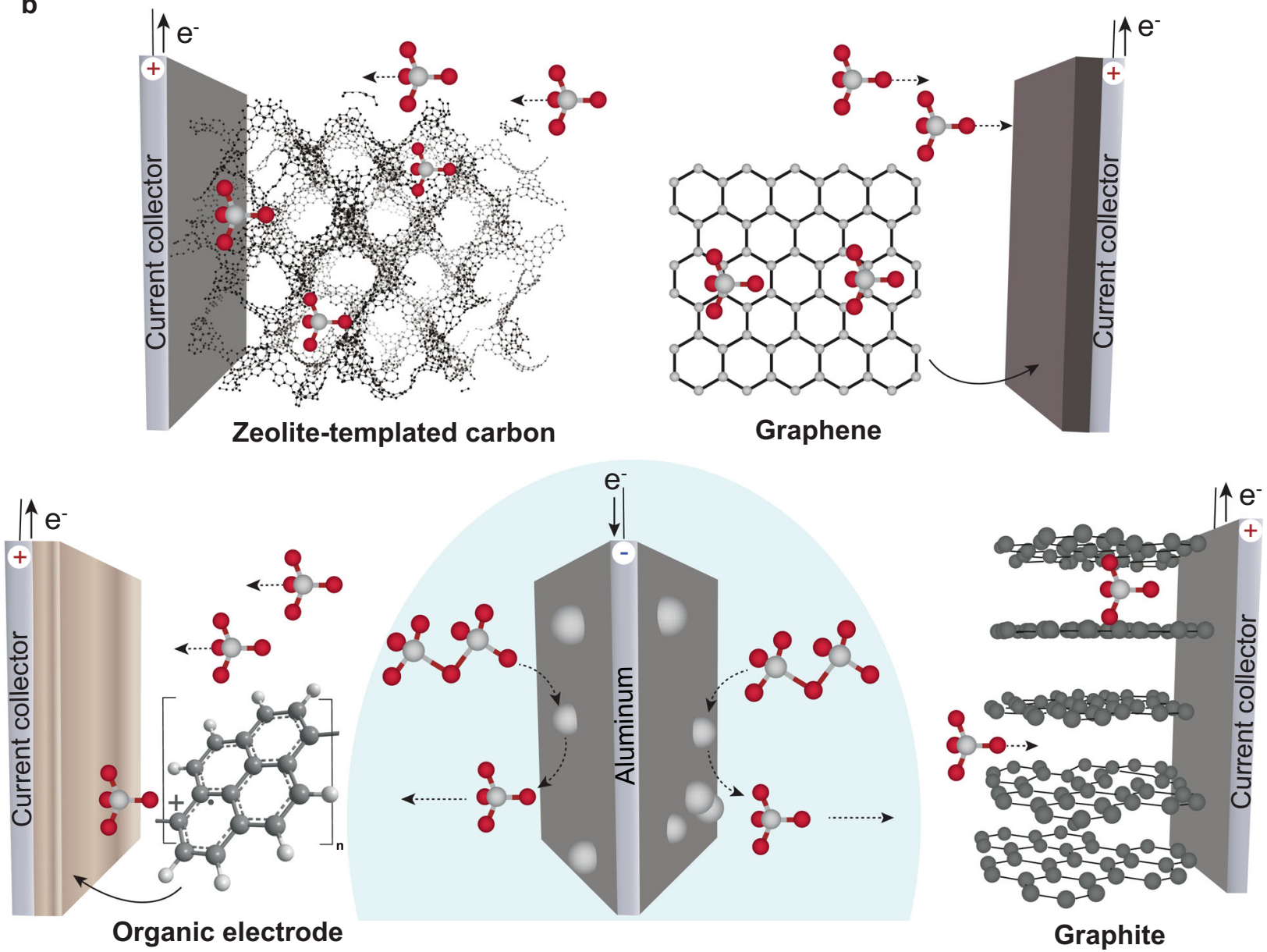

Fig. 1 Schematics of different classes of Al electrolytes and working principle of ADIBs. a Schematic illustration of the different classes of Lewis bases used for the preparation of Al electrolytes in ADIBs. Chlorine, carbon, hydrogen, and nitrogen atoms are shown in red, gray, white, and green colors, respectively. $\mathbf{b}$ Schematic of the charging process of ADIBs composed of aluminum foil at the negative electrode, graphite/graphene/zeolite-templated carbon/polypyrene at the positive electrode, and a chloroaluminate ionic liquid electrolyte. Chlorine and aluminum atoms are shown in red and gray colors, respectively. 
Table 1 Comparison of various Al electrolytes for ADIBs with respect to their density, viscosity, ionic conductivity, theoretical charge storage capacity, and cost.

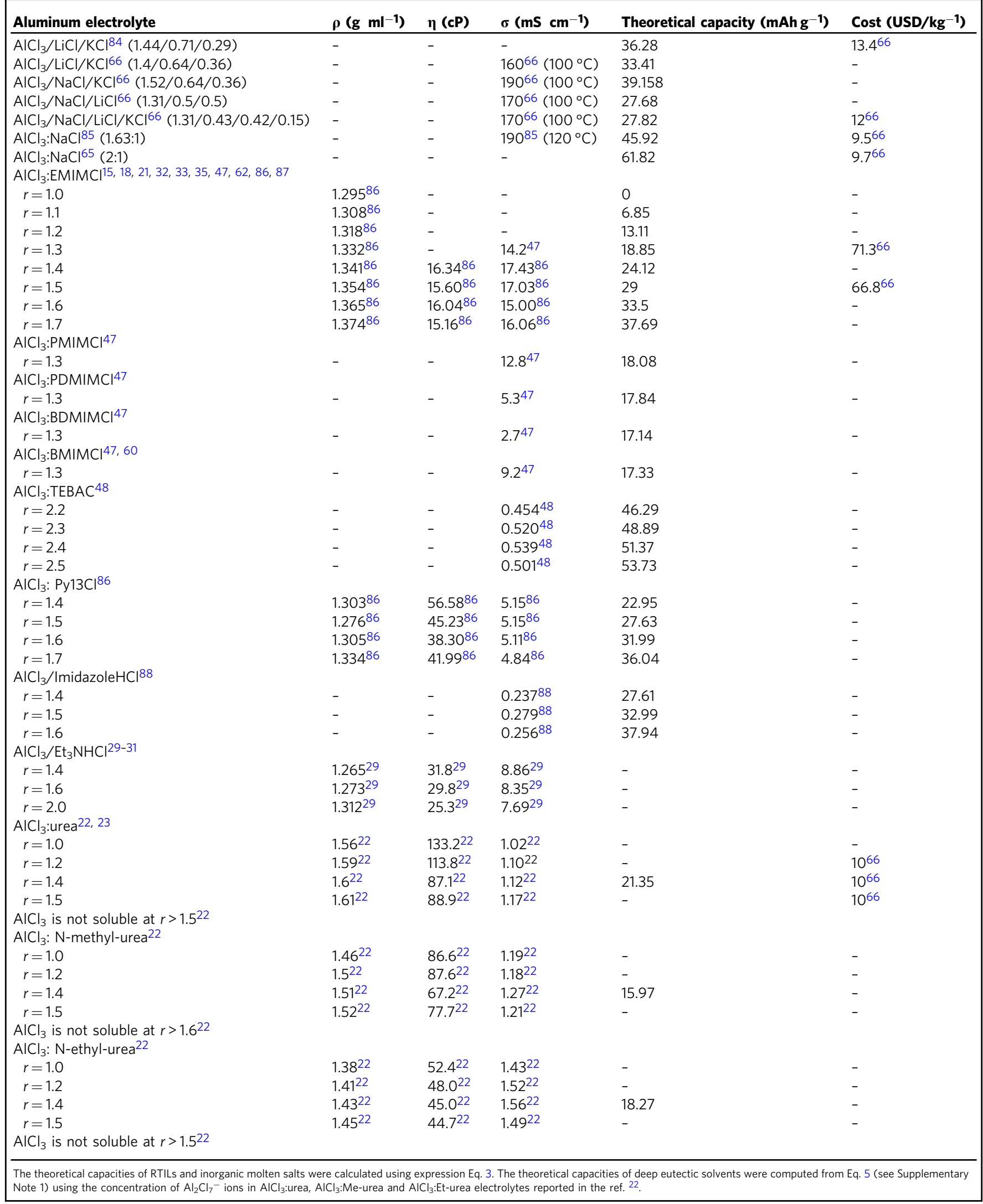


sharply indicating the end of the $\mathrm{Al}$ plating process caused by the depletion of $\mathrm{Al}_{2} \mathrm{Cl}_{7}{ }^{-}$ions at the negative electrode. Importantly, the voltage profile at the negative electrode $\left(E_{\mathrm{CE}}\right)$ for the graphite-limited cell was constant during the entire charge, with a small overpotential

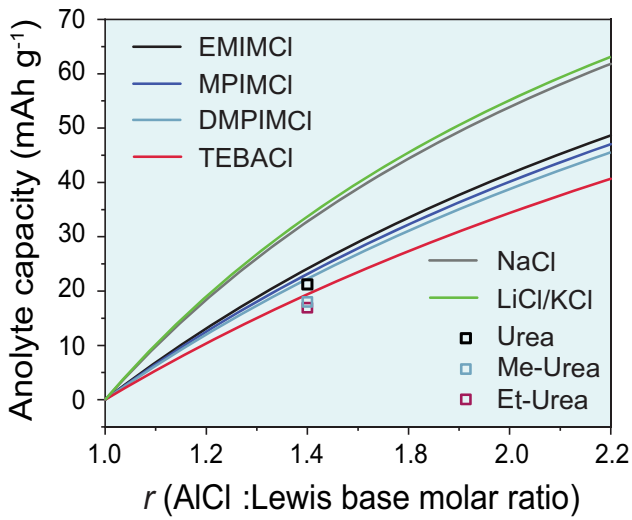

Fig. 2 The charge storage capacity of the RTILs, inorganic molten salts and deep eutectic solvents versus their acidity $(\boldsymbol{r})$. RTILs: $\mathrm{AlCl}_{3}: 1-$-ethyl-3methylimidazolium chloride (EMIMCl), $\mathrm{AlCl}_{3}$ :1-methyl-3-propylimidazolium chloride (MPIMCl), $\mathrm{AlCl}_{3}: 1,2$-dimethyl-3-propylimidazolium chloroaluminate (DMPIMCl) and $\mathrm{AlCl}_{3}$ :benzyltriethylammonium chloride (TEBACl). The curves for RTILs and inorganic molten salts are computed from Eq. 3. The points for deep eutectic solvents are computed from Eq. 5 (see Supplementary Note 1) using the concentration of $\mathrm{Al}_{2} \mathrm{Cl}_{7}-$ ions in $\mathrm{AlCl}_{3}:$ urea, $\mathrm{AlCl}_{3}: \mathrm{Me}$-urea and $\mathrm{AlCl}_{3}$ : Et-urea electrolytes reported in the ref. 22 .
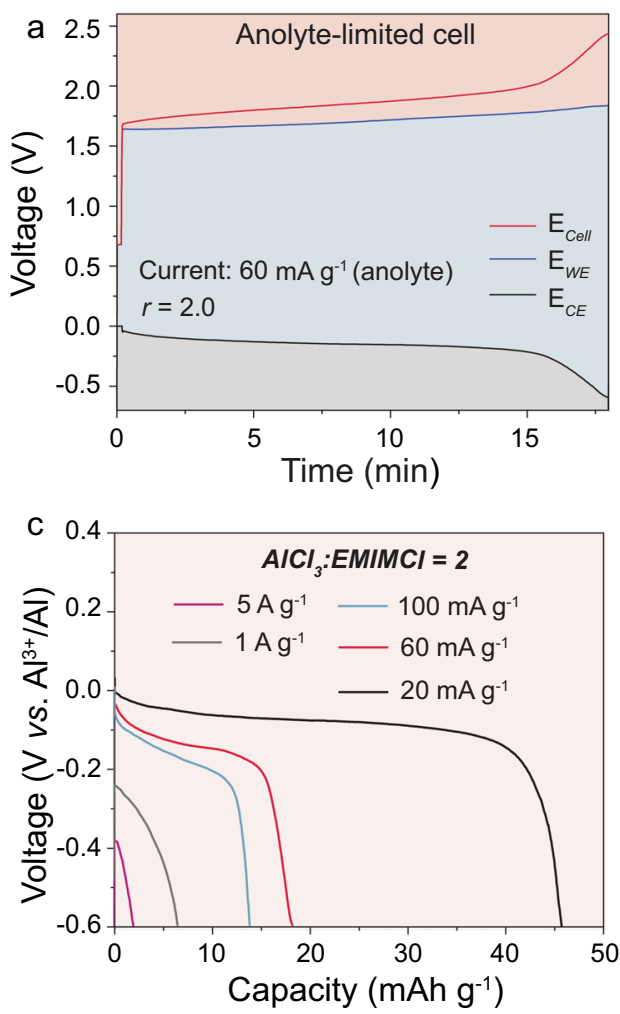

of $<50 \mathrm{mV}$ (Fig. 3b) pointing to the access of $\mathrm{Al}_{2} \mathrm{Cl}_{7}{ }^{-}$ions at the negative electrode. Using this approach, Kravchyk et al..$^{58}$ performed rate capability measurements of anolyte-limited full cells at different current densities ranging from 5 to $20 \mathrm{~mA} \mathrm{~g}^{-1}$ for the $\mathrm{AlCl}_{3}$ : EMIMCl ionic liquid formulations with $r=1.3-2.0$ (see Fig. 3c, d). These experiments revealed two main points. First, as expected, the higher capacities of chloroaluminate melts could be obtained only using highly acidic formulations. For instance, the charge storage capacity of the $\mathrm{AlCl}_{3}: \mathrm{EMIMCl}$ anolyte with $r=1.3$ was measured to be ca. $21 \mathrm{mAh} \mathrm{g}^{-1}$ at a current density of $20 \mathrm{~mA} \mathrm{~g}^{-1}$. In contrast, at $r=2$, the capacity was ca. $46 \mathrm{mAh} \mathrm{g}^{-1}$. These results indicate that the highest energy density of the ADIBs can be obtained using chloroaluminate ionic liquids with $r=2$, and, therefore, future works on ADIBs should be focused on the most acidic formulations. Second, the applied current density affects the charge storage capacity of the anolyte. This is reflected in the significant deviation in the voltage profiles of the negative electrode at high currents (Fig. 3a). As a result, low charge storage capacities (ca. 10-14\% from theoretical values) were obtained at very high current densities of $1 \mathrm{~A} \mathrm{~g}^{-1}$. These results suggest that the frequent statements regarding the high power density of ADIBs are not fully correct. Specifically, at high current densities, a significant drop in the energy density of ADIBs is foreseen. The latter is caused by the rate capability limitations of both the chloroaluminate ionic liquid anolytes and the cathodes of ADIB. In fact, these observations show that the charge storage capacities of the anolyte significantly deviate from the theoretical value at charge current densities higher than $20 \mathrm{~mA} \mathrm{~g}^{-1}$.

Apart from the charge storage capacity, the acidity of the chloroaluminate ionic liquid electrolytes strongly influences their ionic conductivity. For instance, as revealed by Ferrera et al. ${ }^{59}$ for
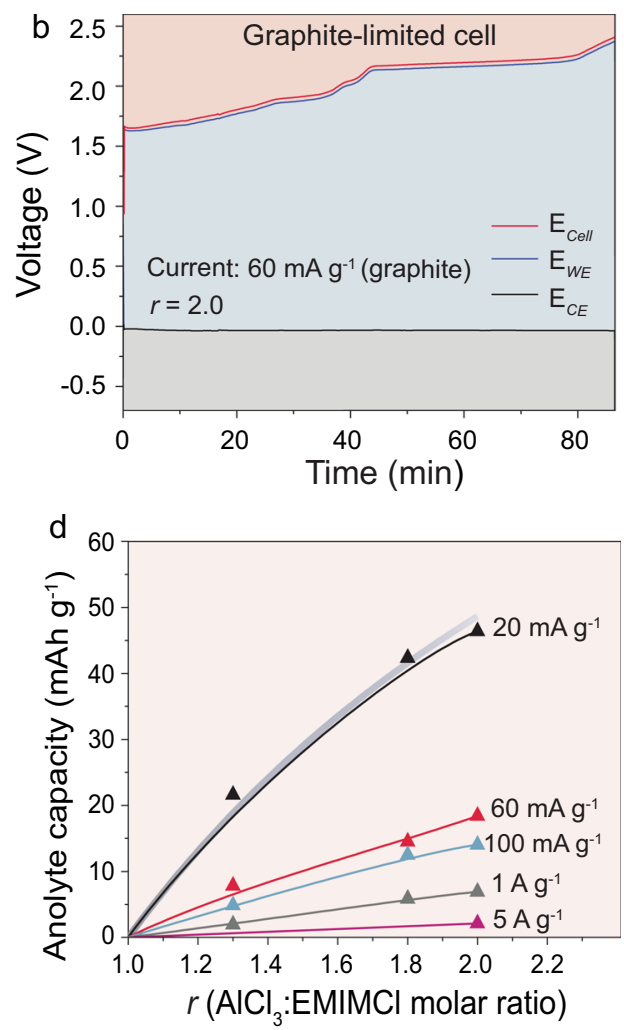

Fig. 3 Electrochemical performance of AICI3:EMIMCI chloroaluminate ionic liquid. a, b Galvanostatic voltage profiles for the $\mathrm{AICl}$ : $\mathrm{EMIMCl}$ chloroaluminate ionic liquid ( $E_{\mathrm{CE}}$, negative electrode), graphite $\left(E_{\mathrm{WE}}\right.$, positive electrode), and full cell $\left(E_{\mathrm{Cell}}\right)$ vs. the Al reference electrode in anolyte-limited (a) and graphite-limited (b) cell configurations. c Galvanostatic discharge curves of the $\mathrm{AlCl}_{3}: \mathrm{EMIMCl}$ anolyte (negative electrode) measured in the anolyte-limited cell configuration at different currents in combination with graphite and aluminum as the working (positive) and the reference electrodes, respectively. $\mathbf{d}$ Specific gravimetric capacities of the $\mathrm{AICl}_{3}: \mathrm{EMIMCl}$ anolyte with $r=1.3,1.8$, and 2.0 measured at different currents. The gray line shows the theoretical capacity of the $\mathrm{AICl}_{3}: \mathrm{EMIMCl}$ anolyte computed from Eq. 3. Adapted from ref. $58, \mathrm{ACS}$. 
the $\mathrm{AlCl}_{3}-\mathrm{EMIMCl}$ chloroaluminate ionic liquid, its conductivity gradually decreases from 20 to $10 \mathrm{mS} \mathrm{cm}^{-1}$ at room temperature upon increasing the $\mathrm{AlCl}_{3} / \mathrm{EMIMCl}$ molar ratio from 1.1 to 1.7, respectively. Furthermore, it was shown by Wang et al..$^{60}$, that the ionic conductivity increases with decreasing halide ionic radius (from iodide to bromide and chloride anions). Moreover, the acidity variations strongly influence the electrochemical stability window of the electrolyte. Specifically, it has been determined that the oxidation of the $\mathrm{AlCl}_{3}$ : 1-ethyl-buthyl-imidazolium ionic liquid with mole ratios of $1,1.1,1.5$ and 2 takes place at approximately $2.6 \mathrm{~V}$ vs. $\mathrm{Al}^{3+} / \mathrm{Al}$, while for the 0.8 mole ratio, the oxidation starts at $1.75 \mathrm{~V}$ vs. $\mathrm{Al}^{3+} / \mathrm{Al}$. The oxidation stability limit is associated with the chlorine evolution at the cathode side ${ }^{41,61}$. It should be noted that Wang et al. ${ }^{62}$ assessed the $\mathrm{Al}^{3+} / \mathrm{Al}$ redox potential in the $\mathrm{AlCl}_{3}-\mathrm{EMIMCl}$ ionic liquid vs. the standard hydrogen electrode (SHE) using a specially made cell composed of a $\beta$-alumina solid-state electrolyte and $\mathrm{Na}$ reference electrode. It was stated that plating/stripping of aluminum in $\mathrm{AlCl}_{3}-\mathrm{EMIMCl}$ ionic liquid occurs at $-0.7 \mathrm{~V}$ vs. SHE and $2.3 \mathrm{~V}$ vs. $\mathrm{Li}^{+} / \mathrm{Li}$. This $\mathrm{Al}^{3+} / \mathrm{Al}$ redox potential is ca. $1 \mathrm{~V}$ higher than that observed in aqueous solutions.

\section{Inorganic molten salts}

Another type of electrolyte capable of reversible aluminum plating/ stripping electrochemistry are low-cost molten salt eutectics. One of the first investigations of aluminum electrodeposition in molten salt electrolytes was undertaken by Del Duca in $1971^{63}$. This work on $\mathrm{AlCl}_{3}-\mathrm{NaCl}$ and $\mathrm{AlCl}_{3}-(\mathrm{LiCl}-\mathrm{KCl})$ mixtures elucidated the kinetics of aluminum electroplating. Gale et al. ${ }^{64}$ examined the subvalent ion effect during aluminum anodization in molten $\mathrm{AlCl}_{3}-\mathrm{NaCl}$. The melting point of a chloroaluminate eutectic mixture is dependent on its precursors and composition. The typical binary $\mathrm{AlCl}_{3} / \mathrm{NaCl}$ and $\mathrm{AlCl}_{3} / \mathrm{KCl}$ systems melt at above 108 and $128^{\circ} \mathrm{C}$, respectively ${ }^{65}$. The addition of a third/fourth salt to the binary electrolyte can further reduce the melting point. For example, a ternary $\mathrm{AlCl}_{3} / \mathrm{NaCl} / \mathrm{KCl}$ electrolyte (molar ratio: 61/26/13) has been reported to melt below $100^{\circ} \mathrm{C}^{65}$, and the $\mathrm{AlCl}_{3} / \mathrm{LiCl} / \mathrm{KCl}$ system with a molar ratio of 59/29/12 turns entirely liquid at approximately $95^{\circ} \mathrm{C}$. Recently, the quaternary $\mathrm{AlCl}_{3} / \mathrm{NaCl} / \mathrm{LiCl} / \mathrm{KCl}$ inorganic molten salt with the lowest eutectic temperature of less than $75^{\circ} \mathrm{C}$ was also systematically studied as the electrolyte in an ADIB $^{66}$. Apart from the low cost, among the advantages of inorganic molten salts as electrolytes for ADIBs are their low viscosity and high ionic conductivity that facilitate the kinetics of $\mathrm{AlCl}_{4}{ }^{-}$insertion/deinsertion reactions. Additionally, with respect to the charge storage capacity, the lower molar mass of alkali chlorides yields higher values of gravimetric capacity over imidazolium or pyridinium chlorides at the same acidity (Fig. 2).

\section{Deep eutectic solvents}

In the search for a more economical and environmentally sustainable alternative to imidazolium-based RTILs, a new class of ionic liquids, namely, DESs, were recently employed as Al electrolytes for ADIBs $s^{43,44,67}$. They are also known as ionic liquid analogs (ILAs) ${ }^{67}$. DESs can be defined as a mixture of a strongly Lewis acidic metal halide and an oxygen donor amide ligand, such as urea, acting as a Lewis base. Similar to the $\mathrm{AlCl}_{3}-\mathrm{EMIMCl}$ system ${ }^{41}, \mathrm{AlCl}_{3}$-urea forms through the exothermic reaction between $\mathrm{AlCl}_{3}$ and urea according to the following equation:

$$
2 \mathrm{AlCl}_{3}+2 \text { urea } \rightarrow \mathrm{AlCl}_{4}^{-}+\left[\mathrm{AlCl}_{2}(\text { urea })_{2}\right]^{+} .
$$

The comprehensive characterization of DESs by both Raman $^{22,24,27,68}$ and $\mathrm{NMR}^{22,23,68}$ spectroscopies have revealed that only $\mathrm{AlCl}_{4}{ }^{-}$are present in the $\mathrm{AlCl}_{3}$-urea DESs at an $\mathrm{AlCl}_{3} /$ urea ratio of 1.0 (neutral). However, as the acidity of the melt increases through the addition of $\mathrm{AlCl}_{3}$, the concentration of the $\mathrm{Al}_{2} \mathrm{Cl}_{7}{ }^{-}$species gradually increases when compared to the concentration of the $\mathrm{AlCl}_{4}{ }^{-}$species (Fig. 4a). The highest molar ratio (r) between the $\mathrm{AlCl}_{3}$ and urea that forms an ionic liquid is ca. $1.5: 1^{22}$. Importantly, as revealed by $\mathrm{Ng}$ et al..$^{27}$, Al electroplating takes place only in the acidic melts $\left(\mathrm{AlCl}_{3} /\right.$ urea $\left.>1.1\right)$. Similar observations have also been reported in other $\mathrm{AlCl}_{3}$-amide systems ${ }^{69}$. Aiming to identify which species are responsible for $\mathrm{Al}$ electrodeposition, Dai et al. ${ }^{22}$ performed operando Raman spectroscopy measurements of $\mathrm{AlCl}_{3}$-urea DESs $\left(\mathrm{AlCl}_{3} / \mathrm{urea}=1.4\right)$ during $\mathrm{Al}$ deposition. Upon $\mathrm{Al}$ plating $\left(0\right.$ to $\left.-0.5 \mathrm{~V} \mathrm{vs.} \mathrm{Al}^{3+} / \mathrm{Al}\right)$, a large decrease in the intensity of the $\mathrm{Al}_{2} \mathrm{Cl}_{7}^{-}$peak $\left(313 \mathrm{~cm}^{-1}\right)$ and a corresponding increase in the $\mathrm{AlCl}_{4}{ }^{-}$peaks $\left(350,445 \mathrm{~cm}^{-1}\right)$ were observed (Fig. $4 \mathrm{~b})$. Upon $\mathrm{Al}$ stripping $\left(0-0.5 \mathrm{~V}\right.$ vs. $\left.\mathrm{Al}^{3+} / \mathrm{Al}\right)$, the exact opposite processes were observed, namely, there was a large intensity increase and decrease in the $\mathrm{Al}_{2} \mathrm{Cl}_{7}{ }^{-}$and the $\mathrm{AlCl}_{4}{ }^{-}$peaks, respectively; no changes to any other peaks were detected. According to Dai's observations, the Al electrodeposition/stripping processes in $\mathrm{AlCl}_{3}$-urea DESs can be described as follows: $4 \mathrm{Al}_{2} \mathrm{Cl}_{7}^{-}+3 \mathrm{e}^{-} \leftrightarrow 7 \mathrm{AlCl}_{4}^{-}+\mathrm{Al}$. We note that previously 23,26 , it had been assumed that the cationic aluminum species $\left[\mathrm{AlCl}_{2}(\text { area })_{2}\right]^{+}$were responsible for the $\mathrm{Al}$ electroplating reaction. This conclusion is in line with the work of Chu et al. ${ }^{70}$, whereby the $\mathrm{Al}$ plating pathways were investigated by density functional theory (DFT) calculations (Fig. 4c, d). Considering the difference in the dissociation energy barriers of $\mathrm{Al}_{2} \mathrm{Cl}_{7}^{-}$and $\left[\mathrm{AlCl}_{2}(\text { urea })_{2}\right]^{+}$is $0.28 \mathrm{eV}$, it has been assumed that the dissociation of $\left[\mathrm{AlCl}_{2}(\mathrm{urea})_{2}\right]^{+}$is less kinetically preferred, therefore, favoring the $\mathrm{Al}$ plating through the $\mathrm{Al}_{2} \mathrm{Cl}_{7}^{-}$reduction. From this perspective, taking into consideration the concentration of $\mathrm{Al}_{2} \mathrm{Cl}_{7}{ }^{-}$in the acidic $\mathrm{AlCl}_{3}$-urea DESs, the charge storage capacity equals ca. $21 \mathrm{mAh} \mathrm{kg}^{-1}$ (for $\mathrm{AlCl}_{3} / \mathrm{urea}=1.4$ ). This value can be derived from Eq. 5 (see Supplementary Note 1) using the concentration of $\mathrm{Al}_{2} \mathrm{Cl}_{7}{ }^{-}$ions in $\mathrm{AlCl}_{3}:$ Urea DES reported in the ref. ${ }^{22}$. For $\mathrm{AlCl}_{3}: \mathrm{Me}$-urea and $\mathrm{AlCl}_{3}$ :Et-urea anolytes, one can obtain similar capacities of ca. $16 \mathrm{mAh} \mathrm{g}^{-1}$ and $18 \mathrm{mAh} \mathrm{g}^{-1}$, respectively.

In addition to $\mathrm{AlCl}_{3}$-urea DESs, several articles have been published reporting the ability of acetamide (AcAm) to form eutectic mixtures when mixed with $\mathrm{AlCl}_{3}$, yielding the reversible electrodeposition of aluminum ${ }^{28,71}$. As stated in ref. ${ }^{28}$, the $\mathrm{AlCl}_{3}-\mathrm{AcAm}$ DES comprises the anionic $\mathrm{AlCl}_{4}{ }^{-}$and $\mathrm{Al}_{2} \mathrm{Cl}_{7}{ }^{-}$ species as well as complexed aluminum cationic species, such as $\left[\mathrm{AlCl}_{2}(\mathrm{AcAm})_{2}\right]^{+}$. Another eutectic $\mathrm{AlCl}_{3}$-organic solvent system with a coordination behavior similar to that of $\mathrm{AlCl}_{3}$-amide is the $\mathrm{AlCl}_{3}$-diglyme electrolyte, which also supports reversible $\mathrm{Al}$ deposition/dissolution ${ }^{72,73}$. The active species in this electrolyte are $\mathrm{AlCl}_{2}(\text { diglyme })_{2}{ }^{+}$cations, which are paired with the $\mathrm{AlCl}_{4}{ }^{-}$ anions.

Considering the low cost of DESs and their environmental friendliness, energy storage systems that utilize DES electrolytes will have significant economic and environmental cost advantages over conventional RTILs. However, such systems have a relatively low electrochemical stability window of $2.2 \mathrm{~V}$ vs. $\mathrm{Al}^{3+} / \mathrm{Al}$ in comparison with that of dialkylimidazolium chloridebased RTILs $22,23,27$. The latter are stable up to $\sim 2.45 \mathrm{~V}$ vs. $\mathrm{Al}^{3+} / \mathrm{Al}^{62}$. Apart from this, the conductivity of the $\mathrm{AlCl}_{3}$-amide systems is rather poor at room temperature (see Table 1) $25,43,74$ The lower conductivity and the sluggish kinetics of the DES electrolytes have been ascribed to their relatively low concentration of active ionic species as well as strong coordination interactions. Atomistic simulations demonstrated that aluminum ions in the RTILs have a weaker coordination and form $\mathrm{Al}-\mathrm{Cl}$ complexes with a low stability compared to those in some molecular solvents, and this contributes to the facile ion transport and dissociation ${ }^{75}$. 

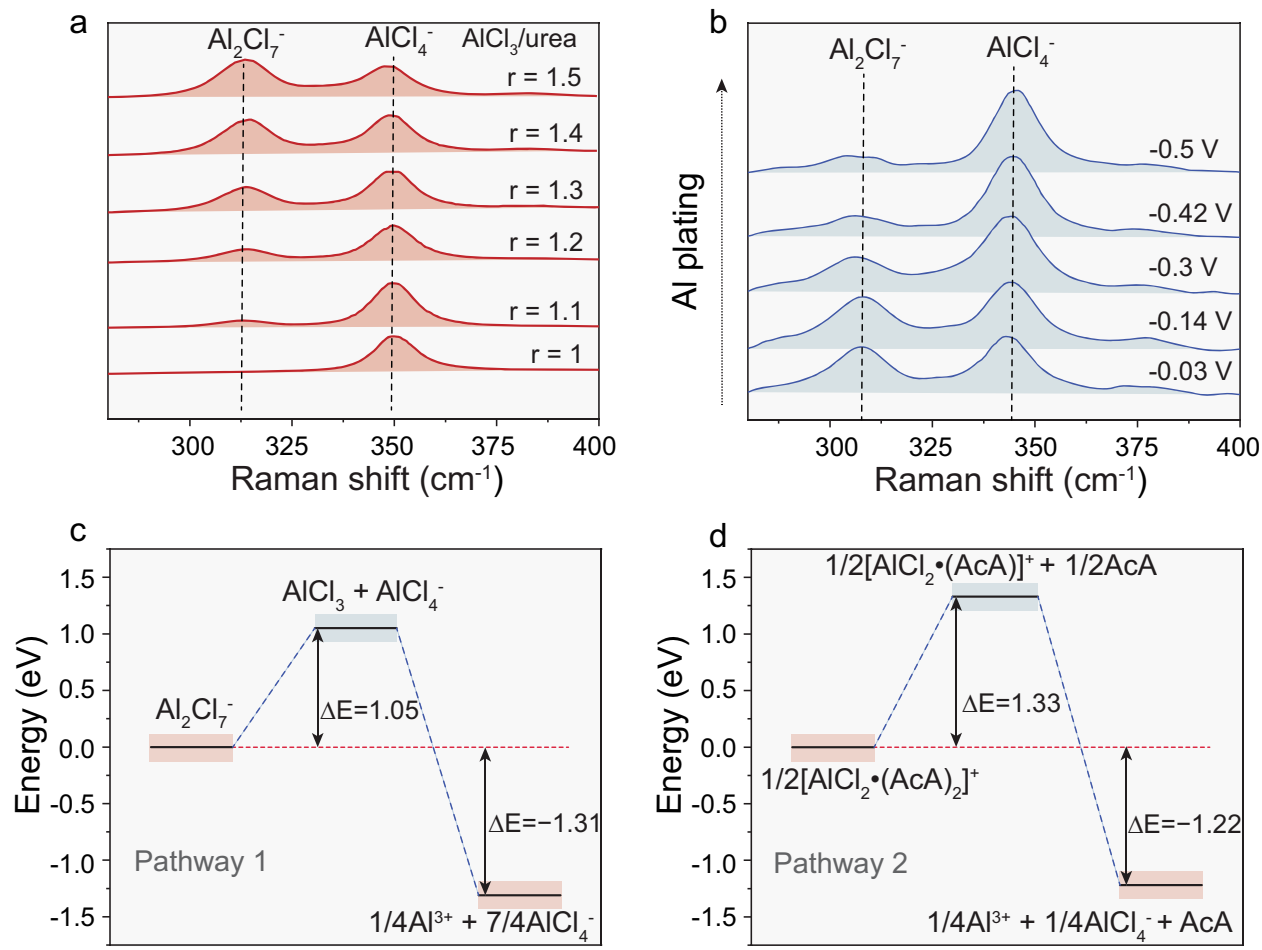

Fig. 4 Raman spectroscopy measurements and Al plating pathways of deep eutectic solvents. a Raman spectra of the $\mathrm{AICl} 3 / \mathrm{urea}$ anolyte $(r=1.0,1.1,1.3$, 1.4, and 1.5); Adapted from ref. ${ }^{27}$, Elsevier. b Operando Raman spectroscopy of the $\mathrm{AlCl}_{3} /$ urea anolyte $(r=1.4)$ during Al plating at different voltages vs. $\mathrm{Al}^{3+} / \mathrm{Al}$. The Raman spectra are normalized to the urea $\mathrm{C}-\mathrm{N}$ symmetric stretch peak at $1050 \mathrm{~cm}^{-1}$. Adapted from ref. ${ }^{22}$, Wiley. c, $\mathbf{d}$ Energy profiles of the dissociation reactions of $\mathrm{Al}_{2} \mathrm{Cl}_{7}-$ (c) and $\left[\mathrm{AlCl}_{2} \cdot(\mathrm{AcA})_{2}\right]^{+}$(d). Adapted from ref. ${ }^{70}$, Elsevier.

\section{Corrosion and current collectors}

One of the main practical issues to address for the realization of cell prototypes of ADIBs is the high reactivity and corrosivity of aluminum anolytes. For instance, the coin-type cells composed of stainless steel corrode in chloroaluminate melts, requiring the employment of corrosion-free battery cases. Furthermore, contrary to the LIBs, where the $\mathrm{Al}$ foil is considered as an established current collector, the current collector for ADIBs at the positive electrode is still under development. Earth-abundant metals, such as aluminum and iron, are easily oxidized in aluminum anolytes at the high voltages of $4.5-5.25 \mathrm{~V}$ vs. $\mathrm{Li}^{+} / \mathrm{Li}$ being employed during positive electrode operation ${ }^{76-78}$. Therefore, oxidatively stable conductive materials such as tungsten, molybdenum, and glassy carbon are typically utilized in ADIBs ${ }^{79,80}$. Of note, it has recently been suggested to use titanium nitride (TiN) as a compelling current collector for ADIBs. As reported by Wang et al. ${ }^{62}$, TiN coated on a stainless steel or flexible polyimide substrate can be fabricated by a low-cost and scalable method, such as magnetron sputtering. The TiN oxidative stability in the $\mathrm{AlCl}_{3}$ : EMIMCl ionic liquid is on par with that of $\mathrm{W}$ and Mo current collectors. Notably, graphitic electrodes without a current collector were also proposed by Di-Yan Wang et al. ${ }^{81}$ as an alternative approach to address the oxidation issues. So-called freestanding natural graphite films were fabricated by graphite slurry tape casting on the $\mathrm{Cu}$ foil following its etching in an iron chloride $\left(\mathrm{FeCl}_{3}\right)$ solution.

Moreover, the research on the chemical stability of Al foil on the negative side of the AGDIB in acidic RTILs was performed recently by Tak et al. ${ }^{82,83}$. It has been demonstrated that $\mathrm{Al}$ surface corrodes in chloroaluminate melts. Furthermore, the corrosion enhances significantly upon increasing their acidity. Importantly, the works of Tak et al. ${ }^{82,83}$, pointed to the fact that additional research efforts should be carried out to mitigate or entirely suppress the reaction of $\mathrm{Al}$ with chloroaluminate electrolytes. The quest for non-corrosive electrolyte formulations, therefore, continues.

\section{Outlook}

Although significant advances were accomplished recently on $\mathrm{Al}$ electrolytes for ADIBs, substantial room remains for the improvement in their gravimetric/volumetric charge storage capacity and the efficiency of $\mathrm{Al}$ plating/stripping. We note that ionic melts used in ADIBs are not just electrolytes (ion-conductors), but represent an electrochemically active, capacity- and rate-limiting battery component. In this context, further research should be focused on finding the practical amounts of the electrolyte needed for the operation of ADIBs. Notably, most of the studies presented in the literature have employed a 2-10-fold excess of the electrolyte required to match the charge storage capacity of the positive electrode (cathode-limited cell). Such tests are acceptable for research purposes, but they do not provide correct and practically relevant information on achievable energy/ power densities or the cycling stability of ADIBs. It is also apparent that future research should focus on the decrease in the redox potential of the $\mathrm{Al}$ plating/stripping being ca. $1 \mathrm{~V}$ higher ( $-0.7 \mathrm{~V}$ vs. SHE) than that in aqueous solutions $(-1.66 \mathrm{~V}$ vs. SHE). Additionally, we suggest that subsequent work should stress the other issues associated with ADIB technology, one being the incompatibility of most metallic current collectors with the corrosive $\mathrm{Al}$ electrolytes. For instance, aluminum and stainless steel slowly oxidize in the $\mathrm{AlCl}_{3}$ :EMIMCl ionic liquid when electrochemically polarized up to $2.5 \mathrm{~V}$ vs. $\mathrm{Al}^{3+} / \mathrm{Al}$. Thus far, only tungsten, molybdenum, glassy carbon, chromium, and titanium nitrides have been identified as electrochemically stable current collectors in such batteries. In this framework, we note that any oxidation stability issues in the current collectors that cause a severe decrease in the coulombic efficiency of ADIBs will have a profound effect on their electrochemical performance, which is 
almost ignored in scientific publications. Towards this end, we state that all these advancements on $\mathrm{Al}$ electrolytes should be achieved at a low cost to keep the overall cost-competitiveness of ADIBs.

Received: 1 May 2020; Accepted: 28 July 2020;

Published online: 28 August 2020

\section{References}

1. Chen, H. et al. Progress in electrical energy storage system: a critical review. Prog. Nat. Sci. 19, 291-312 (2009)

2. Palomares, V. et al. Na-ion batteries, recent advances and present challenges to become low cost energy storage systems. Energy Environ. Sci. 5, 5884-5901 (2012).

3. Kravchyk, K. V., Zünd, T., Wörle, M., Kovalenko, M. V. \& Bodnarchuk, M. I. $\mathrm{NaFeF}_{3}$ nanoplates as low-cost sodium and lithium cathode materials for stationary energy storage. Chem. Mater. 30, 1825-1829 (2018).

4. Hosaka, T., Kubota, K., Hameed, A. S. \& Komaba S. Research development on K-ion batteries. Chem. Rev. 120, 6358-6466 (2020)

5. Mao, M., Gao, T., Hou, S. \& Wang, C. A critical review of cathodes for rechargeable Mg batteries. Chem. Soc. Rev. 47, 8804-8841 (2018).

6. Dubey, R. J. C. et al. Zeolite-templated carbon as a stable, high power magnesium-ion cathode material. ACS Appl. Mater. Interfaces 11, 39902-39909 (2019).

7. Elia, G. A. et al. An overview and future perspectives of aluminum batteries. Adv. Mater. 28, 7564-7579 (2016).

8. Ambroz, F., Macdonald, T. J. \& Nann, T. Trends in aluminium-based Intercalation batteries. Adv. Energy Mater. 7, 1602093 (2017).

9. Das, S. K., Mahapatra, S. \& Lahan, H. Aluminium-ion batteries: developments and challenges. J. Mater. Chem. A 5, 6347-6367 (2017)

10. Walter, M., Kovalenko, M. V. \& Kravchyk, K. V. Challenges and benefits of post-lithium-ion batteries. N. J. Chem. 44, 1677-1683 (2020).

11. Zafar, Z. A. et al. Cathode materials for rechargeable aluminum batteries: current status and progress. J. Mater. Chem. A 5, 5646-5660 (2017).

12. Fu, L. et al. Advances of aluminum based energy storage systems. Chin. J. Chem. 35, 13-20 (2017).

13. Wang, Y. et al. Emerging non-lithium ion batteries. Energy Storage Mater. 4, 103-129 (2016).

14. Muñoz-Torrero, D., Palma, J., Marcilla, R. \& Ventosa, E. A critical perspective on rechargeable Al-ion battery technology. Dalton Trans. 48, 9906-9911 (2019).

15. Wang, $\mathrm{S}$. et al. Anatase $\mathrm{TiO}_{2}$ nanorods as cathode materials for aluminum-ion batteries. ACS Appl. Nano Mater. 2, 6428-6435 (2019).

16. Auborn, J. J. An ambient temperature secondary aluminum electrode: Its cycling rates and its cycling efficiencies. J. Electrochem. Soc. 132, 598 (1985).

17. Chen, H. et al. Oxide film efficiently suppresses dendrite growth in aluminumion battery. ACS Appl. Mater. Interfaces 9, 22628-22634 (2017).

18. Kravchyk, K. V., Wang, S., Piveteau, L., Kovalenko, M. V. Efficient aluminum chloride-natural graphite battery. Chem. Mater. 29, 4484-4492 (2017).

19. Fouletier, M. \& Armand, M. Electrochemical method for characterization of graphite-aluminium chloride intercalation compounds. Carbon 17, 427-429 (1979).

20. Gifford, P. R. An aluminum/chlorine rechargeable cell employing a room temperature molten salt electrolyte. J. Electrochem. Soc. 135, 650 (1988).

21. Lin, M.-C. et al. An ultrafast rechargeable aluminium-ion battery. Nature $\mathbf{5 2 0}$ 324-328 (2015).

22. Angell, M., Zhu, G., Lin, M.-C., Rong, Y. \& Dai, H. Ionic liquid analogs of $\mathrm{AlCl}_{3}$ with urea derivatives as electrolytes for aluminum batteries. Adv. Funct. Mater. 30, 1901928.

23. Angell, M. et al. High Coulombic efficiency aluminum-ion battery using an $\mathrm{AlCl}_{3}$-urea ionic liquid analog electrolyte. Proc. Natl Acad. Sci. U.S.A. 114, 834-839 (2017).

24. Jiao, H., Wang, C., Tu, J., Tian, D. \& Jiao, S. A rechargeable Al-ion battery: Al/ molten $\mathrm{AlCl}_{3}$-urea/graphite. Chem. Commun. 53, 2331-2334 (2017).

25. Li, J., Tu, J., Jiao, H., Wang, C. \& Jiao, S. Ternary $\mathrm{AlCl}_{3}$-Urea-[EMIm] $\mathrm{Cl}$ ionic liquid electrolyte for rechargeable aluminum-ion batteries. J. Electrochem. Soc. 164, A3093-A3100 (2017)

26. Wang, C., Li, J., Jiao, H., Tu, J. \& Jiao, S. The electrochemical behavior of an aluminum alloy anode for rechargeable $\mathrm{Al}$-ion batteries using an $\mathrm{AlCl}_{3}$-urea liquid electrolyte. RSC Adv. 7, 32288-32293 (2017).

27. $\mathrm{Ng}, \mathrm{K}$. L. et al. A low-cost rechargeable aluminum/natural graphite battery utilizing urea-based ionic liquid analog. Electrochim. Acta 327, 135031 (2019).
28. Canever, N., Bertrand, N. \& Nann, T. Acetamide: a low-cost alternative to alkyl imidazolium chlorides for aluminium-ion batteries. Chem. Commun. $\mathbf{5 4}$ 11725-11728 (2018)

29. $\mathrm{Xu}, \mathrm{H}$. et al. Low-cost $\mathrm{AlCl}_{3} / \mathrm{Et}_{3} \mathrm{NHCl}$ electrolyte for high-performance aluminum-ion battery. Energy Storage Mater. 17, 38-45 (2019).

30. Gan, F. et al. Low cost ionic liquid electrolytes for rechargeable aluminum/ graphite batteries. Ionics 25, 4243-4249 (2019).

31. Xia, S., Zhang, X.-M., Huang, K., Chen, Y.-L. \& Wu, Y.-T. Ionic liquid electrolytes for aluminium secondary battery: Influence of organic solvents. $J$. Electroanal. Chem. 757, 167-175 (2015).

32. Wang, S., Kravchyk, K. V., Krumeich, F. \& Kovalenko, M. V. Kish graphite flakes as a cathode material for an aluminum chloride-graphite battery. ACS Appl. Mater. Interfaces 9, 28478-28485 (2017).

33. Stadie, N. P., Wang, S., Kravchyk, K. V. \& Kovalenko, M. V. Zeolite-templated carbon as an ordered microporous electrode for aluminum batteries. ACS Nano 11, 1911-1919 (2017).

34. Yu, X., Wang, B., Gong, D., Xu, Z. \& Lu, B. Graphene nanoribbons on highly porous 3D graphene for high-capacity and ultrastable Al-ion batteries. Adv. Mater. 29, 1604118 (2017).

35. Walter, M., Kravchyk, K. V., Böfer, C., Widmer, R. \& Kovalenko, M. V. Polypyrenes as high-performance cathode materials for aluminum batteries. Adv. Mater. 30, 1705644 (2018).

36. Hudak, N. S. Chloroaluminate-doped conducting polymers as positive electrodes in rechargeable aluminum batteries. J. Phys. Chem. C. 118, 5203-5215 (2014)

37. Lai, P. K. \& Skyllas-Kazacos, M. Aluminium deposition and dissolution in aluminium chloride-n-butylpyridinium chloride melts. Electrochim. Acta 32, 1443-1449 (1987).

38. Chao-Cheng, Y. Electrodeposition of aluminum in molten $\mathrm{AlCl}_{3}-\mathrm{n}-$ butylpyridinium chloride electrolyte. Mater. Chem. Phys. 37, 355-361 (1994).

39. Zhao, Y. \& VanderNoot, T. J. Electrodeposition of aluminium from nonaqueous organic electrolytic systems and room temperature molten salts. Electrochim. Acta 42, 3-13 (1997).

40. Zein El Abedin, S., Moustafa, E. M., Hempelmann, R., Natter, H. \& Endres, F. Electrodeposition of nano- and microcrystalline aluminium in three different air and water stable ionic liquids. ChemPhysChem 7, 1535-1543 (2006).

41. Jiang, T., Chollier Brym, M. J., Dubé, G., Lasia, A. \& Brisard, G. M. Electrodeposition of aluminium from ionic liquids. I: electrodeposition and surface morphology of aluminium from aluminium chloride $\left(\mathrm{AlCl}_{3}\right)$-1-ethyl3-methylimidazolium chloride $([\mathrm{EMIm}] \mathrm{Cl})$ ionic liquids. Surf. Coat. Tech. 201, 1-9 (2006)

42. Jiang, T., Chollier Brym, M. J., Dubé, G., Lasia, A. \& Brisard, G. M. Electrodeposition of aluminium from ionic liquids. II: studies on the electrodeposition of aluminum from aluminum chloride $\left(\mathrm{AICl}_{3}\right)$ trimethylphenylammonium chloride (TMPAC) ionic liquids. Surf. Coat. Tech. 201, 10-18 (2006).

43. Abbott, A. P., Harris, R. C., Hsieh, Y.-T., Ryder, K. S. \& Sun, I. W. Aluminium electrodeposition under ambient conditions. Phys. Chem. Chem. Phys. 16, 14675-14681 (2014)

44. Abood, H. M. A., Abbott, A. P., Ballantyne, A. D. \& Ryder, K. S. Do all ionic liquids need organic cations? Characterisation of $\left[\mathrm{AlCl}_{2} \cdot \mathrm{nAmide}\right]^{+} \mathrm{AlCl}_{4}{ }^{-}$and comparison with imidazolium based systems. Chem. Commun. 47, 3523-3525 (2011).

45. Bakkar, A. \& Neubert, V. A new method for practical electrodeposition of aluminium from ionic liquids. Electrochem. Commun. 51, 113-116 (2015).

46. Fang, Y. et al. An $\mathrm{AlCl} 3$ based ionic liquid with a neutral substituted pyridine ligand for electrochemical deposition of aluminum. Electrochim. Acta 160, 82-88 (2015)

47. Yang, C. et al. Substituent effect of imidazolium ionic liquid: a potential strategy for high coulombic efficiency Al battery. J. Phys. Chem. C. 123 11522-11528 (2019)

48. Xu, C., Li, J., Chen, H. \& Zhang, J. Benzyltriethylammonium chloride electrolyte for high-performance Al-ion batteries. ChemNanoMat 5, 1367-1372 (2019)

49. Lv, Z. et al. A high discharge voltage dual-ion rechargeable battery using pure $\left(\mathrm{DMPI}^{+}\right)\left(\mathrm{AlCl}_{4}^{-}\right)$ionic liquid electrolyte. J. Power Sources 418, 233-240 (2019).

50. Kravchyk, K. V. \& Kovalenko, M. V. Rechargeable dual-Ion batteries with graphite as a cathode: key challenges and opportunities. Adv. Energy Mater. 9, 1901749 (2019)

51. Zhao, X., Zhao-Karger, Z., Fichtner, M., Shen, X. Halide-based materials and chemistries for rechargeable batteries. Angew. Chem. Int. Ed. 59, 2-50.

52. Bitenc, J. et al. Concept and electrochemical mechanism of an $\mathrm{Al}$ metal anode -organic cathode battery. Energy Storage Mater. 24, 379-383 (2020).

53. Leisegang, $\mathrm{T}$. et al. The aluminum-ion battery: a sustainable and seminal concept? Front. Chem. 7, https://doi.org/10.3389/fchem.2019.00268 (2019).

54. Sui, Y. et al. Dual-ion batteries: the emerging alternative rechargeable batteries. Energy Storage Mater. 25, 1-32 (2019). 
55. Zhao, H., Xu, J., Yin, D. \& Du, Y. Electrolytes for batteries with earthabundant metal anodes. Chem.: Eur. J. 24, 18220-18234 (2018).

56. Chen, C.-Y., Tsuda, T., Kuwabata, S. \& Hussey, C. L. Rechargeable aluminum batteries utilizing a chloroaluminate inorganic ionic liquid electrolyte. Chem. Commun. 54, 4164-4167 (2018).

57. Liu, Z. et al. Carbon nanoscrolls for aluminum battery. ACS Nano 12, 8456-8466 (2018).

58. Kravchyk K. V., Seno C., Kovalenko M. V. Limitations of chloroaluminate ionic liquid anolytes for aluminum-graphite dual-ion batteries. ACS Energy Lett., 545-549 (2020).

59. Ferrara, C., Dall'Asta, V., Berbenni, V., Quartarone, E. \& Mustarelli, P. Physicochemical characterization of $\mathrm{AlCl}_{3}$-1-Ethyl-3-methylimidazolium chloride ionic liquid electrolytes for aluminum rechargeable batteries. J. Phys. Chem. C. 121, 26607-26614 (2017)

60. Wang, $H$. et al. Anion-effects on electrochemical properties of ionic liquid electrolytes for rechargeable aluminum batteries. J. Mater. Chem. A 3, 22677-22686 (2015).

61. Carlin, R. T. Nucleation and morphology studies of aluminum deposited from an ambient-temperature chloroaluminate molten salt. J. Electrochem. Soc. 139, 2720 (1992).

62. Wang, S. et al. Aluminum chloride-graphite batteries with flexible current collectors prepared from earth-abundant elements. Adv. Sci. 5, 1700712 (2018).

63. Del Duca, B. S. Electrochemical behavior of the aluminum electrode in molten salt electrolytes. J. Electrochem. Soc. 118, 405-411 (1971).

64. Gale, R. J. \& Osteryoung, R. A. Investigation of subvalent ion effects during aluminum anodization in molten $\mathrm{NaCl}-\mathrm{AlCl}_{3}$ solvents. J. Electrochem. Soc. 121, 983-987 (1974)

65. Tu, J. et al. The effects of anions behaviors on electrochemical properties of $\mathrm{Al} /$ graphite rechargeable aluminum-ion battery via molten $\mathrm{AlCl}_{3}-\mathrm{NaCl}$ liquid electrolyte. J. Electrochem. Soc. 164, A3292-A3302 (2017).

66. Tu, J., Wang, J., Zhu, H. \& Jiao, S. The molten chlorides for aluminumgraphite rechargeable batteries. J. Alloys Compd. 821, 153285 (2020).

67. Smith, E. L., Abbott, A. P. \& Ryder, K. S. Deep eutectic solvents (DESs) and their applications. Chem. Rev. 114, 11060-11082 (2014).

68. Coleman, F., Srinivasan, G. \& Swadźba-Kwaśny, M. Liquid coordination complexes formed by the heterolytic cleavage of metal halides. Angew. Chem. Int. Ed. 52, 12582-12586 (2013).

69. $\mathrm{Li}, \mathrm{M}$. et al. $\mathrm{AlCl}_{3} /$ amide ionic liquids for electrodeposition of aluminum. $J$. Solid State Electrochem. 21, 469-476 (2017).

70. Chu, W. et al. A low-cost deep eutectic solvent electrolyte for rechargeable aluminum-sulfur battery. Energy Storage Mater. 22, 418-423 (2019).

71. $\mathrm{Li}, \mathrm{M}$. et al. Electrodeposition of aluminum from $\mathrm{AlCl}_{3} /$ acetamide eutectic solvent. Electrochim. Acta 180, 811-814 (2015).

72. Kitada, A., Nakamura, K., Fukami, K. \& Murase, K. $\mathrm{AlCl}_{3}$-dissolved diglyme as electrolyte for room-temperature aluminum electrodeposition. Electrochemistry 82, 946-948 (2014).

73. Kitada, A., Nakamura, K., Fukami, K. \& Murase, K. Electrochemically active species in aluminum electrodeposition baths of $\mathrm{AlCl}_{3} /$ glyme solutions. Electrochim. Acta 211, 561-567 (2016).

74. Li, M. et al. Electrodeposition behavior of aluminum from urea-acetamidelithium halide low-temperature molten salts. Electrochim. Acta 185, 148-155 (2015).

75. Kamath, G., Narayanan, B. \& Sankaranarayanan, S. K. R. S. Atomistic origin of superior performance of ionic liquid electrolytes for $\mathrm{Al}$-ion batteries. Phys. Chem. Chem. Phys. 16, 20387-20391 (2014).

76. Tseng, C.-H. et al. Corrosion behaviors of materials in aluminum chloride-1ethyl-3-methylimidazolium chloride ionic liquid. Electrochem. Commun. 12, 1091-1094 (2010).

77. Reed, L. D. \& Menke, E. The roles of $\mathrm{V}_{2} \mathrm{O}_{5}$ and stainless steel in rechargeable Al-ion batteries. J. Electrochem. Soc. 160, A915-A917 (2013).

78. Shi, J., Zhang, J. \& Guo, J. Avoiding pitfalls in rechargeable aluminum batteries research. ACS Energy Lett. 4, 2124-2129 (2019).
79. Gao, T. et al. A rechargeable Al/S battery with an ionic-liquid electrolyte. Angew. Chem. Int. Ed. 55, 9898-9901 (2016).

80. Wang, S. et al. High-performance aluminum-ion battery with CuS@C microsphere composite cathode. ACS Nano 11, 469-477 (2017).

81. Wang, D.-Y. et al. Advanced rechargeable aluminium ion battery with a highquality natural graphite cathode. Nat. Commun. 8, 14283 (2017).

82. Choi S., Go H., Lee G., Tak Y. Electrochemical properties of an aluminum anode in an ionic liquid electrolyte for rechargeable aluminum-ion batteries. Phys. Chem. Chem. Phys. 19, 8653-8656 (2017).

83. Lee, D., Lee, G. \& Tak, Y. Hypostatic instability of aluminum anode in acidic ionic liquid for aluminum-ion battery. Nanotechnology 29, 36LT01 (2018).

84. Wang, J., Zhang, X., Chu, W., Liu, S. \& Yu, H. A sub- $100{ }^{\circ} \mathrm{C}$ aluminum ion battery based on a ternary inorganic molten salt. Chem. Commun. 55, 2138-2141 (2019)

85. Song, Y. et al. A long-life rechargeable $\mathrm{Al}$ ion battery based on molten salts. J. Mater. Chem. A 5, 1282-1291 (2017).

86. Zhu, G. et al. Rechargeable aluminum batteries: effects of cations in ionic liquid electrolytes. RSC Adv. 9, 11322-11330 (2019).

87. Elia, G. A. et al. Insights into the reversibility of aluminum graphite batteries. J. Mater. Chem. A 5, 9682-9690 (2017).

88. $\mathrm{Xu}, \mathrm{C}$. et al. A high capacity aluminum-ion battery based on imidazole hydrochloride electrolyte. ChemElectroChem 6, 3350-3354 (2019).

\section{Acknowledgements}

This research is part of the activities of SCCER HeE, which is financially supported by Innosuisse - Swiss Innovation Agency.

\section{Author contributions}

K.V.K. conceptualized and wrote the original draft. K.V.K. and M.V.K. discussed and revised the manuscript.

\section{Competing interests}

The authors declare no competing interests.

\section{Additional information}

Supplementary information is available for this paper at https://doi.org/10.1038/s42004 020-00365-2.

Correspondence and requests for materials should be addressed to K.V.K. or M.V.K.

Reprints and permission information is available at http://www.nature.com/reprints

Publisher's note Springer Nature remains neutral with regard to jurisdictional claims in published maps and institutional affiliations.

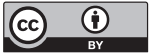

Open Access This article is licensed under a Creative Commons Attribution 4.0 International License, which permits use, sharing, adaptation, distribution and reproduction in any medium or format, as long as you give appropriate credit to the original author(s) and the source, provide a link to the Creative Commons license, and indicate if changes were made. The images or other third party material in this article are included in the article's Creative Commons license, unless indicated otherwise in a credit line to the material. If material is not included in the article's Creative Commons license and your intended use is not permitted by statutory regulation or exceeds the permitted use, you will need to obtain permission directly from the copyright holder. To view a copy of this license, visit http://creativecommons.org/ licenses/by/4.0/.

(c) The Author(s) 2020 